\title{
A hydrodynamic model coupled multiple scenarios for plain river network and its application
}

\author{
Zeng Zhiqiang $^{1 *}$, Liang Ji ${ }^{1}$, Yang Mingxiang ${ }^{2}$, Zeng Zhaocai ${ }^{1}$, Lang $\mathrm{Yu}^{2}$ \\ ${ }^{1}$ Huazhong University of Science and Technology , School of Hydropower \& Information Engineering, Wuhan430074,China; \\ ${ }^{2}$ State Key Laboratory of Simulation and Regulation of Water Cycle in River Basin, China Institute of Water Resources and Hydropower \\ Research, Beijing 100038, China)
}

\begin{abstract}
The plain river network is not only complex in shape but also contains many complex scenarios, such as interval inflow and outflow, hydraulic structures and water storage area, etc., which increases the difficulty of runoff simulation in plain river network. To address this problem, a hydrodynamic (HD) model coupled multiple scenarios that may occur in plain river network was proposed, which was used to simulate the runoff process of the plain river network. To illustrate the proposed model, Xi River was chosen as a study area. We designed some experiments for each scenario, and the experimental results show that simulation results have good consistency with the observation. It is worth noting that the simulation accuracy of the water level is always higher than the simulation accuracy of the flow. Moreover, the runoff simulation accuracy of runoff events with large runoff is relatively high. It turns out that HD model is suitable for runoff simulation of plain river network. In addition, we compared the flood diversion effects of water storage area and sluice, and the results show that the effect of water storage area is more obvious than sluice, and the flood diversion method combined with sluice and water storage area has better flood diversion effect. In conclusion, HD model is good at simulating floodplain storage effects, backwater and the change of water level and flow under the condition of engineering dispatching, which has important guiding significance for flood control in plain river network.
\end{abstract}

\section{Introduction}

Plains account for $12 \%$ of the total land area in China, mainly distributed on both sides of the river and in the coastal areas. The terrain in the plains is low and the river network is crisscrossed. Compared with mountain river networks, river networks in plain areas are more complicated. A tree-like river network and a straight river network dominate the mountainous area, while a complex annular river network dominates the plain area. Obviously, the hydraulic calculation of the plain river network area is more complicated, and there are many hydraulic structures (sluices, pumps, culverts and weirs) in the plain river network area, which further increases the difficulty of hydraulic calculation for the plain river network area (Kałuża et al., 2018). The plains have abundant rainfall and frequent floods. Due to the flat terrain in the plains, after the flooding, the water flow spreads and spreads widely, the flooding speed is slow, and the flooding time is long (Hamilton, 2009a; Hamilton, 2009b; Piper, 2014). In addition, the plain area tends to have a large population density and a relatively developed economy. Once the flood occurs, it will cause immeasurable losses. In summary, the research on flood control and disaster mitigation in plain river network area has very important theoretical and practical significance
(Adamovic et al., 2016; Hardy et al., 2016). Accurately simulating the runoff process of the river network in the plain area will provide strong support for flood control and disaster mitigation in the plain area (Liu et al., 2017; Lohani et al., 2014).

The hydrodynamic model is widely used to simulate the evolution of runoff in rivers (Baugh et al., 2013; de Paiva et al., 2013; Munar et al., 2018). There are many factors affecting the results of hydrodynamic simulation (Radfar et al., 2013; Salunkhe et al., 2018; Zernin et al., 2017), such as interval inflow and outflow(Ajami et al., 2016), hydraulic structures and water storage area(Andrew et al., 2017; Wu et al., 2018), etc. In plain river network area, the complex and various scenarios need to be considered comprehensively. However, there are few studies on hydrodynamic simulation in plain river network under multiple scenarios. Considering a variety of scenarios such as hydraulic structures, interval flow and water storage area that may occur in the plain river network, this paper proposed a hydrodynamic model coupled multiple scenarios for plain river network. To illustrate the proposed model, Xi River was chosen as a study area. Results show that the coupled model is suitable for simulating the runoff process of the plain river network area. At present, the coupling model proposed in this paper has been successfully integrated into the "Anhui Small and Medium River Forecasting and 
Warning System”, and has achieved good application results in practical applications.

\section{Methodology}

Part 2 mainly consists of four modules: (1) Introduce the principle of HD model used in this paper. (2) How to deal with the interval inflow and outflow in the river network.
(3) How to couple various hydraulic structures into HD model. (4) How to deal with the internal boundary, such as concentrative lateral flow, abrupt change of the cross section and the convergence of river and water storage area in plain river network. Fig.1 shows the structure diagram of the HD model coupled multiple scenarios.

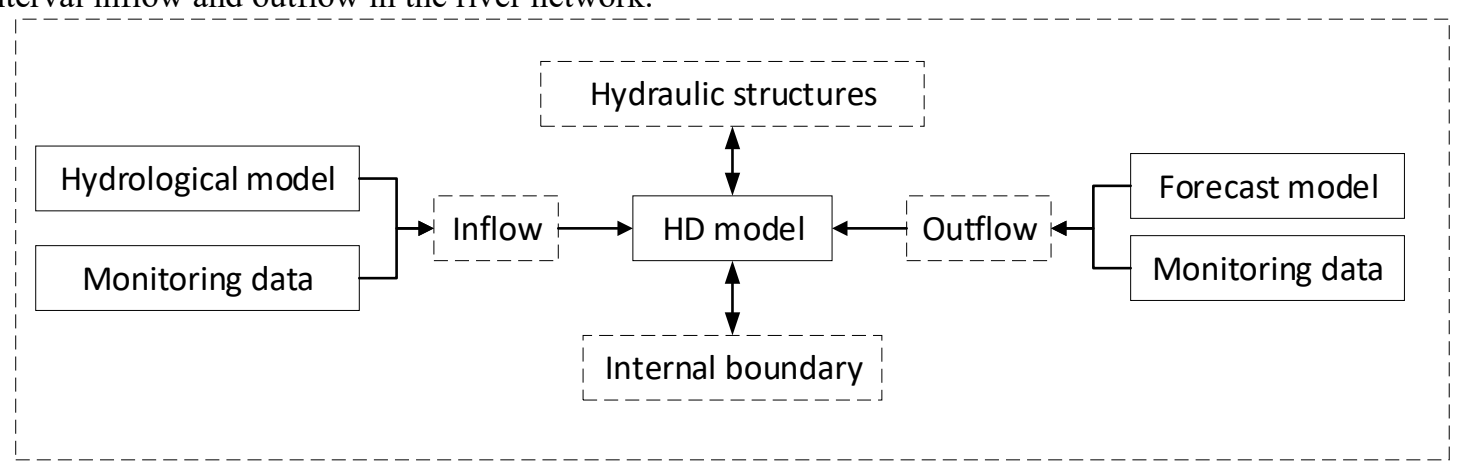

Fig.1 Structure diagram of the HD model coupled multiple scenarios

\subsection{HD model}

HD model is a basic equation describing the one-dimensional unsteady flow motion in a natural channel, consisting of continuity equation (mass conservation) and dynamic equation (momentum conservation). According to the magnitude of the momentum equation, the equation is classified as dynamic wave equation, motion wave equation, diffusion wave equation and inertial wave equation. The full-format dynamic wave equation is universal. Taking into account the actual situation of the plain river network, we uses the full-format dynamic wave equation to simulate the runoff process. Continuity equation and dynamic equation are as follows:

Continuity equation:

$$
B \frac{\partial Q}{\partial x}+\frac{\partial A}{\partial t}=q
$$

Dynamic equation:

$$
\frac{\partial Q}{\partial t}+\frac{\partial\left(\frac{\beta Q^{2}}{A}\right)}{\partial x}+g A \frac{\partial Z}{\partial x}+g A S_{f}=0
$$

Where $\mathrm{Q}$ is discharge; $\mathrm{B}$ is the width of the cross section; $\mathrm{A}$ is cross-sectional area; $\mathrm{q}$ is lateral inflow; $\beta$ is momentum correction factor; $\mathrm{g}$ is acceleration due to gravity; $\mathrm{Z}$ is water surface elevation above horizontal datum; Sf is friction slope; $\mathrm{x}$ is longitudinal distance along the channel length and $t$ is time. The friction slope term $S_{f}$ can be estimated using the Manning's equation.

$$
S_{f}=\frac{n^{2} Q|Q|}{A^{2} R^{4 / 3}}
$$

St. Venant equations are nonlinear hyperbolic partial differential equations, which are generally solved by numerical methods. In many numerical methods, implicit finite-difference method is widely used (Kim and Kawano, 1995; W. Choi and Molinas, 1993). In solving the equations, the finite difference method (Fig.2) is used to separate the equations into linear or nonlinear difference equations, and then the difference equations are solved by Gauss elimination method, chasing method and iterative method. We choose the widely used chasing method to solve the equations.

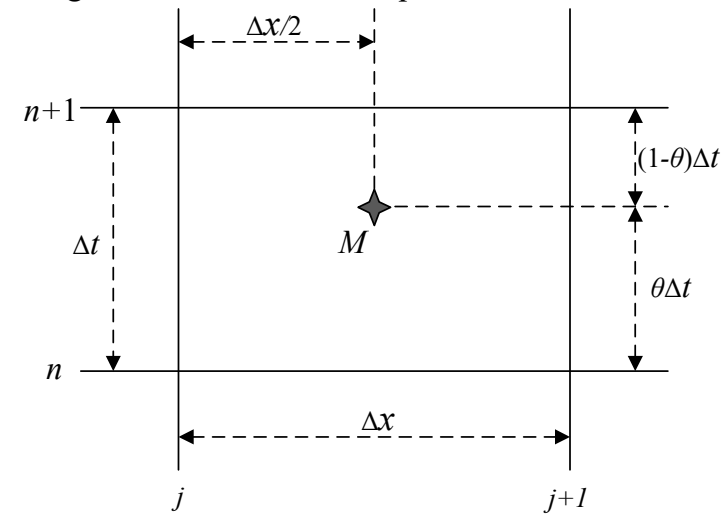

Fig.2 Discrete diagram of the Preissmann differential format

\subsection{Interval inflow and outflow}

Part of the water in the plain river network comes from the interval watersheds on both sides of the river. This part of the water often accounts for a large proportion of the total water volume, so we have to consider the interval inflow and outflow of the plain river network.

Point source is used to define a side stream or inflow that is sometimes variable or constant at a location, such as a water intake and a branch inflow. Distribution source is used to define inflow that is sometimes variable or constant along a certain river, such as a river side seepage and the inflow of slopes. The data of interval inflow and outflow mainly come from actual measurement and forecasting. The forecast will be implemented by coupling hydrological model and HD model. The hydrological model will make the HD model 
not only has the simulation function but also has the forecast function.

The $q$ contained in the continuity equation is the side inflow of the section interval, and the specific physical meaning is the side flow distributed on the unit river length. We will use point source and distribution source to generalize the outflow and inflow of the interval. The mass $M_{\text {in(out) }}$ of the interval flow (inflow and outflow) into the section of the control body as shown in Fig. 2 can be expressed as

$$
M_{\text {in }(o u t)}=\rho q \Delta x \Delta t
$$

\subsection{Hydraulic structures}

The river network in the plain area contains a variety of hydraulic structures, such as sluices, pumps, culverts and weirs. This paper mainly takes the sluices as the representative to consider the role and influence of hydraulic structures in the plain river network. There are three kinds of situations, such as closing sluice, free flow and submerged flow.

Closing sluice:

$$
Q_{i}=Q_{i+1}=0
$$

Free flow:

$$
Q=m b h \sqrt{2 g\left(Z_{i}-Z_{d}\right)}
$$

Submerged flow:

$$
Q=\phi b h \sqrt{2 g\left(Z_{i}-Z_{i+1}\right)}
$$

Where $\mathrm{Q}$ is water discharge through the sluice; $Z_{i}$ is upstream water level; $Z_{d}$ is sluice elevation; $Z_{i+1}$ is downstream water level; $\mathrm{m}$ is the comprehensive flow coefficient; $b$ is the width of sluice; $\phi$ is the submerged coefficient.

The treatment of hydraulic structures is attributed to the chasing factor calculation for special sections of the river containing hydraulic structures. The calculation is based on the compatibility equation of the special river section (conservation of water quantity and conservation of momentum).

\subsection{Processing of internal boundary conditions}

The river network in the plain area generally has the following internal boundary conditions, such as concentrative lateral flow, abrupt change of cross section and convergence of river and water storage area. At these internal boundaries, the equation (1) and (2) are no longer applicable and must be specially treated according to their hydraulic characteristics. The internal boundary condition usually contains two compatible conditions, namely the continuity condition of the flow and the energy conservation condition. The specific processing methods are as follows
Concentrative lateral flow:

$$
\left\{\begin{array}{l}
Z_{i}=Z_{i+1} \\
Q_{i}+Q_{f}=Q_{i+1}
\end{array}\right.
$$

Abrupt change of cross section:

$$
\left\{\begin{array}{l}
Z_{i}=Z_{i+1}=Z_{s} \\
Q_{i+1}=Q_{i}-Q_{s}
\end{array}\right.
$$

Convergence of river and water storage area:

$$
\left\{\begin{array}{l}
Z_{i}+\frac{u_{i}^{2}}{2 g}=Z_{i+1}+\frac{u_{i+1}^{2}}{2 g}+\xi \frac{\left(u_{i}-u_{i+1}\right)^{2}}{2 g} \\
Q_{i}=Q_{i+1}
\end{array}\right.
$$

\subsection{Design simulation experiments}

In order to better verify the model proposed in this paper, we design the following four experiments. These experiments are some typical scenarios in the plain river network area and have good practical significance.

(1) Simulation for the entire area

The simulation for the entire area is designed to verify the overall performance of the model. Only the HD model for the entire area are accurate enough, and the following experiments make more sense. HD model takes into account the outflow and inflow of the interval, the hydraulic structures and some internal boundaries.

(2) Simulation of interval inflow

For a section, design several sets of different inflow conditions, and compare and analyze the water level and flow change process of several sections adjacent to this section.

(3) Simulation of interval outflow

The same to (3), several sets of different outflows are designed for one section, and the water level and flow changes of adjacent sections of the section are compared and analyzed.

(4) Simulation of the influence of sluice regulation on river flow and water level

Control the outflow process of the gate and compare the water level changes under different control modes. In practice, we often need to control the sluice to achieve the purpose of flood control.

(5) Simulation of flood diversion in water storage area

Using water storage areas to divert floods is an effective flood control and disaster mitigation measure. Therefore, we simulated the flood diversion process in the water storage area and assessed the actual effect of flood diversion.

The above-mentioned groups of experiments have done a simulation of typical scenarios in the plain areas, which not only tests the proposed model, but also has guiding significance for actual engineering scheduling. In order to evaluate the accuracy of simulation results, the NSE (Nash and Sutcliffe, 1970) is selected as the objective function, and the NSE is expressed as 


$$
N S E=\left(1-\frac{\sum_{i=1}^{n}\left(A_{i}-\hat{A}_{\mathrm{i}}\right)^{2}}{\sum_{i=1}^{n}\left(A_{i}-\bar{A}_{i}\right)^{2}}\right) \times 100 \%
$$

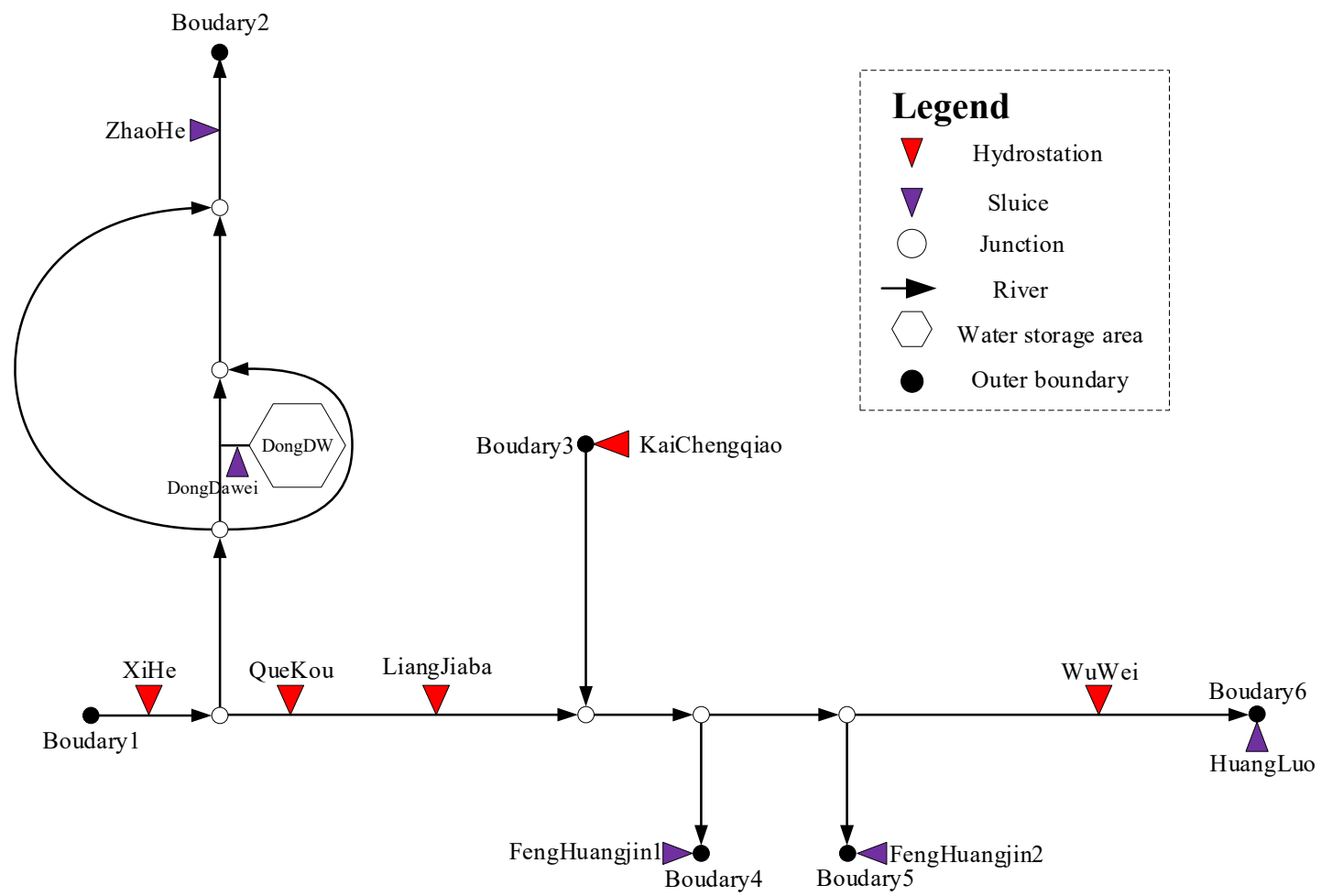

Fig.3 Generalized map of Xi River.

Xi River is located in the Anhui Province and belongs to the left bank of the lower reaches of the Yangtze River. Zhao River and Yong'an River are the two major tributaries of $\mathrm{Xi}$ River. Zhao River, which is 32.8 kilometers long, is a manually excavated river. The elevation of the river bottom is $6.0 \sim 6.4 \mathrm{~m}$, the bottom width is $15 \sim 40 \mathrm{~m}$, and the safe displacement of the river is $155 \sim 245 \mathrm{~m}^{3} / \mathrm{s}$. Zhao river has two sluices (ZhaoHe and DongDawei) and a water storage area (DongDW) surrounded by a circular network. DongDawei controls whether the water is able to flows into the DongDW. The
Where $A_{\mathrm{i}}$ is the observed value, $\hat{A}_{\mathrm{i}}$ is the simulated value, $\bar{A}_{i}$ is the mean observed discharge, and $n$ is the number of values.

\section{Study area and data}

water storage capacity of DongDawei is $2.41 \times 10^{8} \mathrm{~m}^{3}$. Yong'an River is 46.55 kilometers long and has a hydrological station on the river. The main stream of Xi River is from Quekou (a hydrological station) to HuangLuo (a sluice), with a total length of $86 \mathrm{~km}$ and a control area of $626 \mathrm{~km}^{2}$. Four hydrological stations on the main stream for monitoring river water level and flow. There are two small tributaries on the main stream that flow directly into the Yangtze River, and one sluice on each of the two tributaries. The structure of the detailed Xi River is shown in Fig.3.

Table1 The outer boundary condition type of the HD model ("Z" represents water level and "Q" represents flow)

\begin{tabular}{ccccccc}
\hline Name & Boudary1 & Boudary2 & Boudary3 & Boudary4 & Boudary5 & Boudary6 \\
\hline Type & $\mathrm{Z}$ & $\mathrm{Q}$ & $\mathrm{Q}$ & $\mathrm{Q}$ & $\mathrm{Q}$ & $\mathrm{Z}$ \\
\hline
\end{tabular}

$\mathrm{Xi}$ River belongs to the plain area and is suitable for validating the model proposed in this paper. Xi River contains 9 rivers, 396 sections, 5 sluices, 5 hydrological stations and a water storage area. The outer boundary conditions of the HD model are set as shown in Table 1. Observation hydrological data from 2017 to 2018 will be used for simulation of HD model. Four measured runoff events were used to simulate. The statistical information of the simulated events is shown in Table 3 below. Table 2 shows the maximum water level, maximum flow and total water volume for each simulated event. During the simulation, the sluices except DongDawei and FengHuangjin2 are in a normal open state.

Table2 Statistics of four simulation events $\left(\mathrm{Z}(\mathrm{m}), \mathrm{Q}\left(\mathrm{m}^{3} / \mathrm{s}\right)\right.$, Volume $\left.\left(10^{8} \mathrm{~m}^{3}\right)\right)$

\begin{tabular}{cccccccc}
\hline Station name & \multicolumn{2}{c}{ Quekou } & \multicolumn{3}{c}{ LiangJiaba } & \multicolumn{2}{c}{ WuWei } \\
\hline Simulation events & $\operatorname{Max}(\mathrm{Z})$ & Volume & $\operatorname{Max}(\mathrm{Z})$ & $\operatorname{Max}(\mathrm{Q})$ & Volume & Max $(\mathrm{Z})$ & Volume \\
$201605010701(\mathrm{~A})$ & 12.47 & 1.938 & 12.40 & 333.00 & 1.873 & 11.67 & 1.652 \\
$201607021001(\mathrm{~B})$ & 12.65 & 4.402 & 12.64 & 339.00 & 4.445 & 12.44 & 0.725 \\
$201705010701(\mathrm{C})$ & 8.63 & 0.642 & 8.61 & 30.00 & 0.834 & 8.62 & 0.647 \\
\hline
\end{tabular}




\subsection{Results of simulation}

\section{Results and Discussions}

Table3 NSE values of four simulation events

\begin{tabular}{cccccc}
\hline Station name & Quekou & \multicolumn{2}{c}{ LiangJiaba } & WuWei & NSCE/4 \\
\hline Simulation events & $\mathrm{Z}$ & $\mathrm{Z}$ & $\mathrm{Q}$ & $\mathrm{Z}$ & - \\
201605010701(A) & 0.95 & 0.96 & 0.62 & 0.92 & 0.86 \\
$201607021001(\mathrm{~B})$ & 0.98 & 0.98 & 0.68 & 0.99 & 0.91 \\
$201705010701(\mathrm{C})$ & 0.91 & 0.91 & 0.66 & 0.92 & 0.85 \\
201707021001(D) & 0.63 & 0.66 & 0.54 & 0.69 & 0.63 \\
\hline
\end{tabular}

As shown in Table3, the average value of NSE for A, B data will be much larger than the monitoring error of the and $\mathrm{C}$ are greater than 0.75 , indicating that the $\mathrm{HD}$ model is suitable for simulation of plain river networks. From Fig.4, Fig.5 and Fig.6, we can intuitively see that the accuracy of the water level simulation is higher than the accuracy of the flow simulation, which is consistent with the actual situation. Due to the flat terrain in the plain area, the direction of movement of the water flow will alternate between positive and negative. This phenomenon will increase the difficulty of flow monitoring. Therefore, the monitoring error of the flow water level data. At the same time, as shown in Fig. 3 and Fig.5, the range of water level variation is limited, while the fluctuation of flow is exactly the opposite. Among the four simulation events, the simulation accuracy of $\mathrm{B}$ is the highest, and the simulation accuracy of $\mathrm{D}$ is the lowest. B A is the event with the highest peak flow and water level and the largest water volume in all simulation events. The simulation results show that the larger the runoff, the higher the accuracy of the simulation.
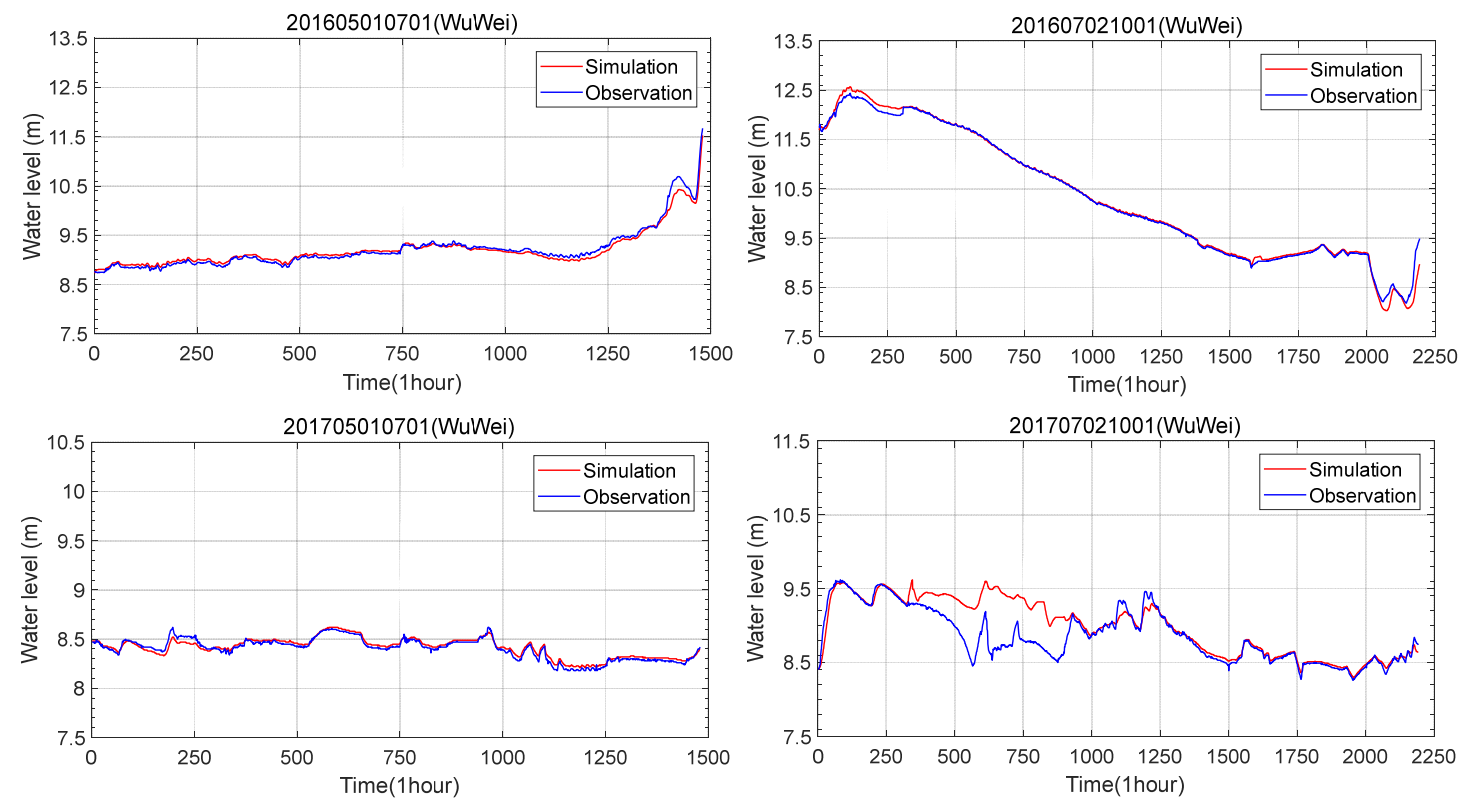

Fig.4 Comparison of measured and simulated results of WuWei station (Water level) 

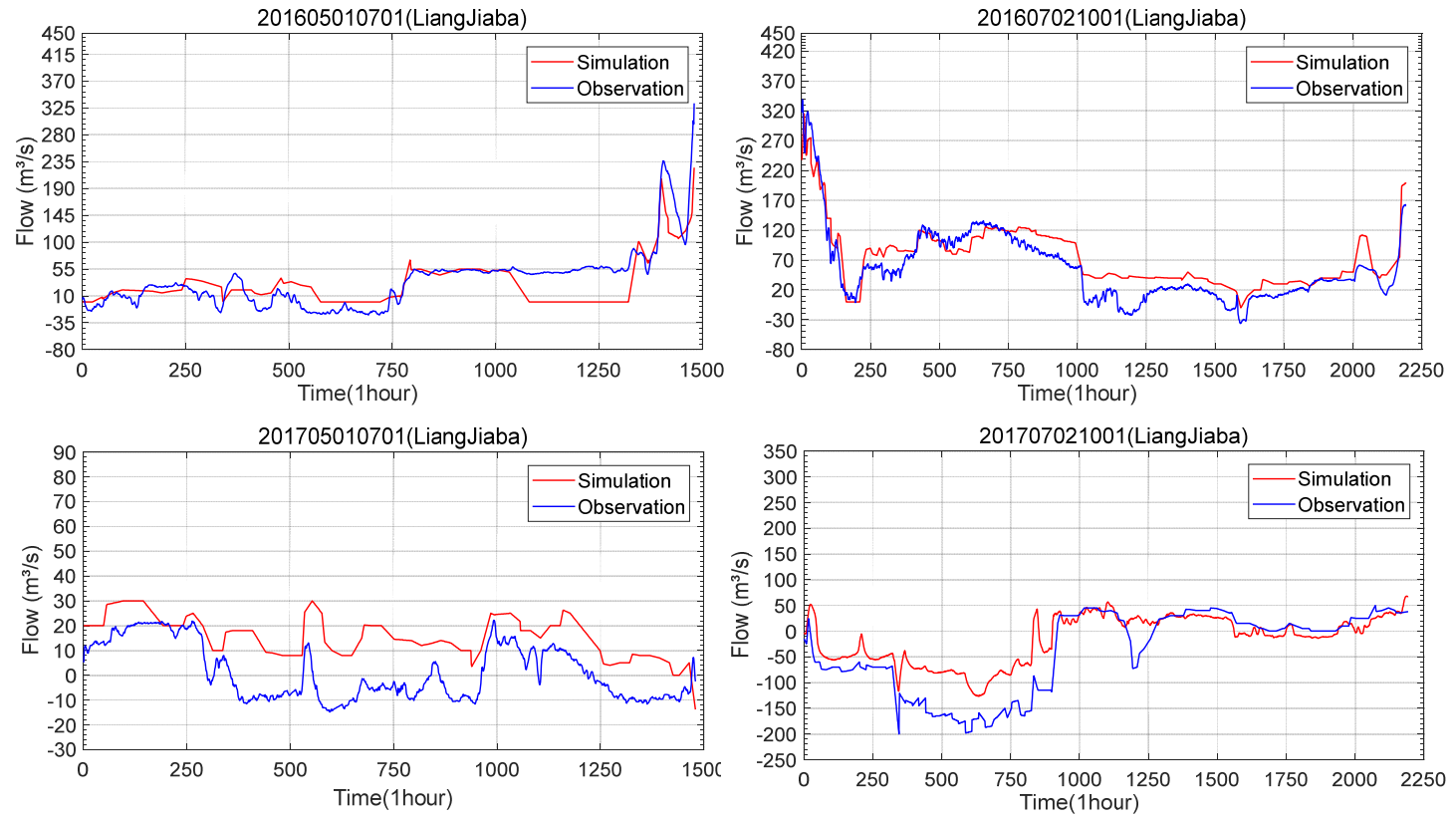

Fig.5 Comparison of measured and simulated results of LiangJiaba station (Flow)
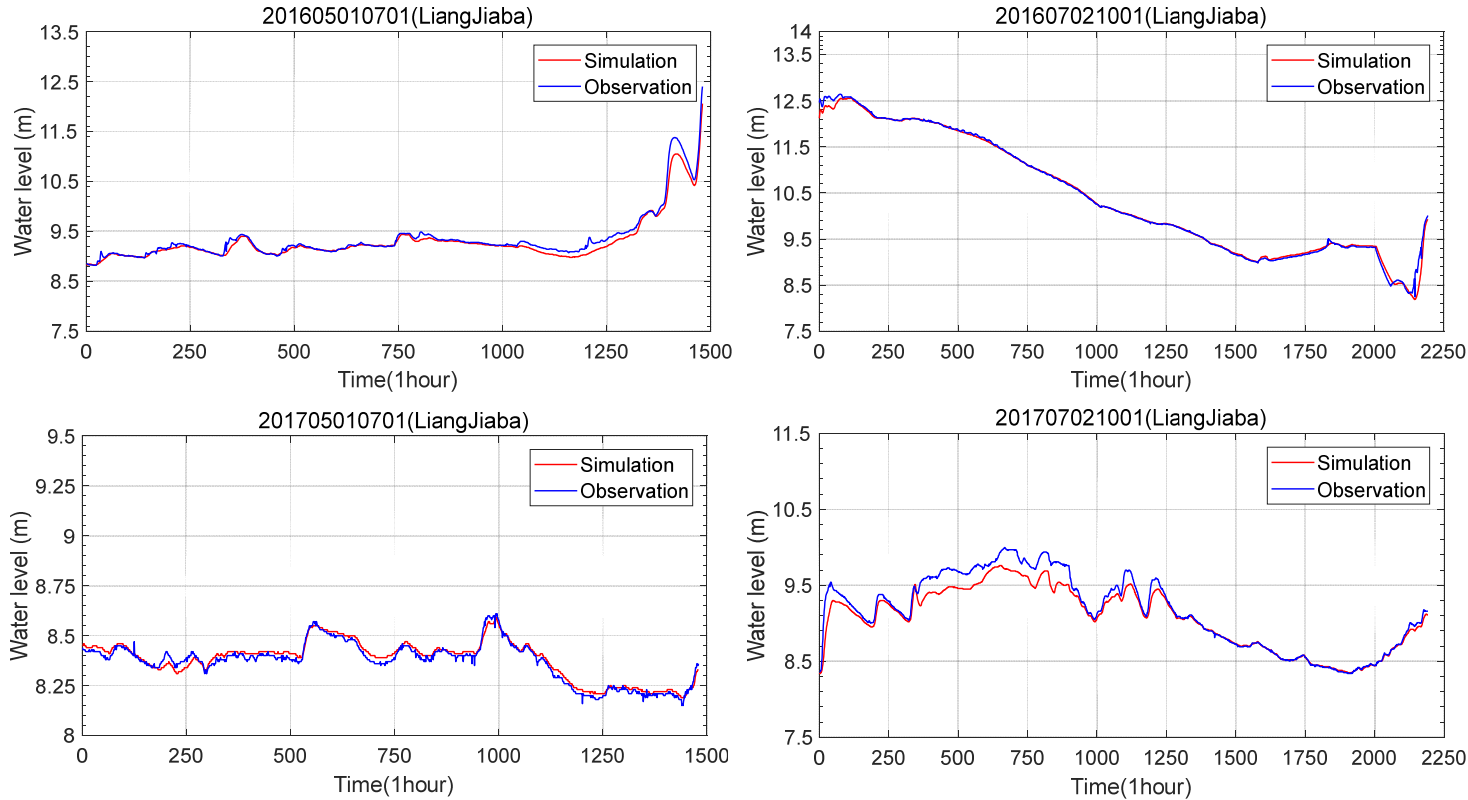

Fig.6 Comparison of measured and simulated results of LiangJiaba station (Water level)

\subsection{Comparative analysis of interval inflow and outflow}



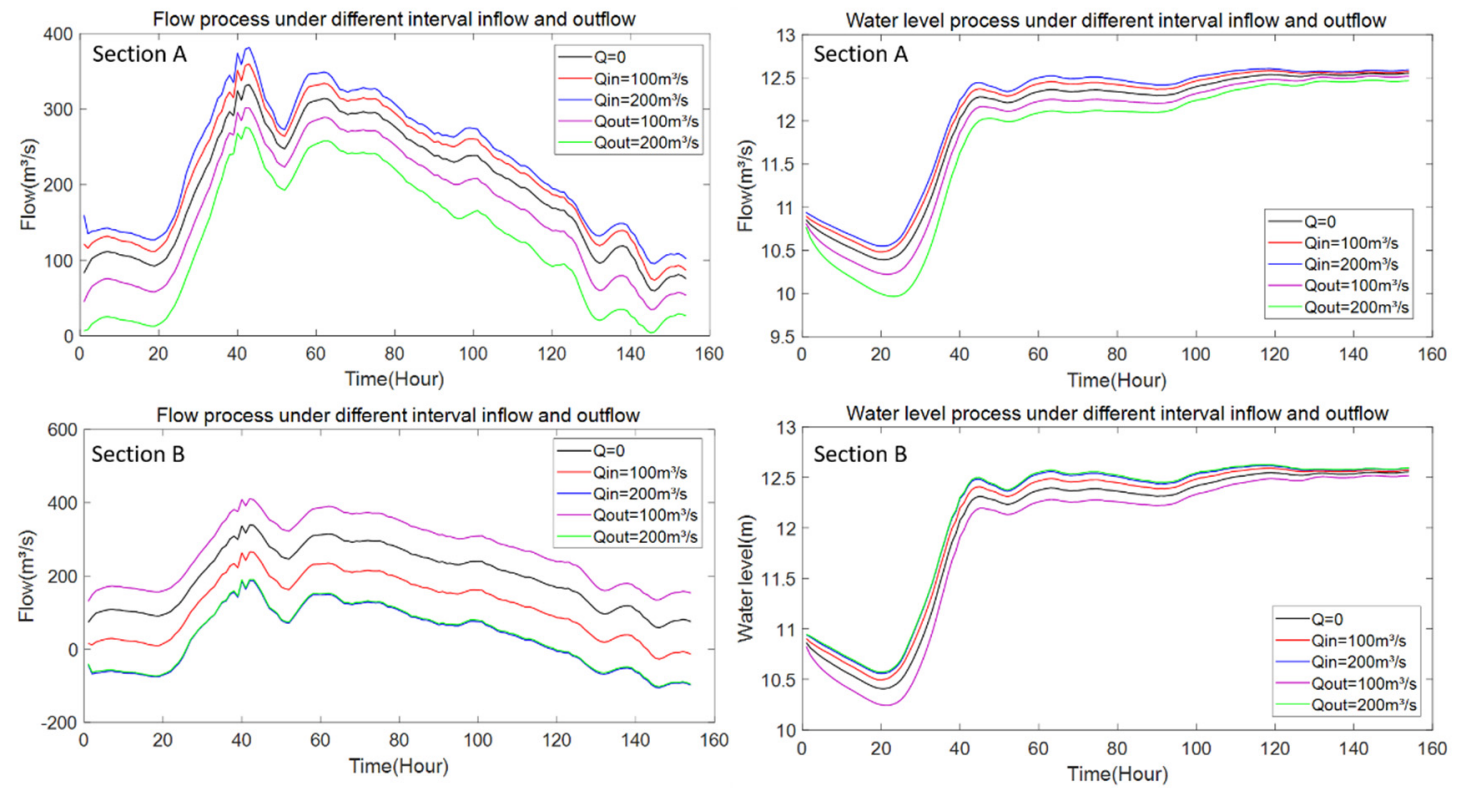

Fig.7 Water level and flow process under different interval inflow and outflow

It can be seen from the Fig.7 that the interval outflow and inflow affect the flow pattern of the entire river network; especially the several sections adjacent to it are the most affected. In this paper, the section located in Liangjiaba station were selected for the analysis of the interval outflow and inflow. Two different sets of inflow and outflow processes are designed as outflow and inflow of section respectively. Fig. 7 shows the variation of water level and flow of adjacent sections under different inflow and outflow processes. The results show that the water level and flow of the upstream section decreased, while the water level and flow of downstream section are increased. During the interval outflow, the water level and flow of the upstream section increased, while the water level and flow of the downstream section decreased. In the case of interval outflow, the water flow

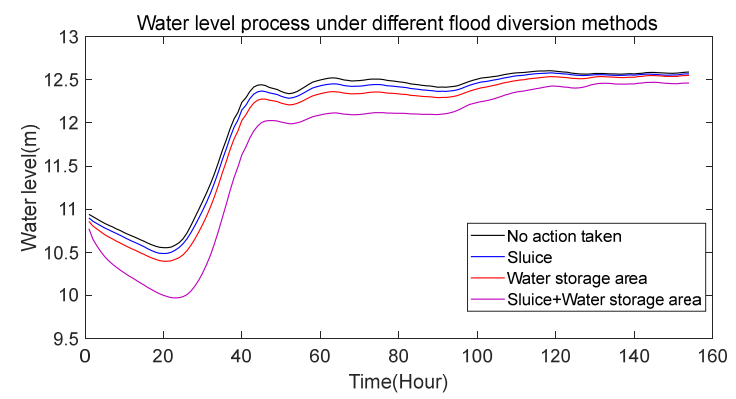

(a)

Fig.8 Water level and flow process under different flood diversion methods.

DongDD with a water storage capacity of $2.41 \times 10^{8} \mathrm{~m}^{3}$ is often used to relieve excessive pressure on river floods. We choose Liangjiaba as the observation point for water level and flow. We show the flood diversion effect of water storage area through a set of experiments. Fig.8(a) show that the overall water level is reduced due to flood diversion by water storage area, and the flood diversion effect is obvious.

The effect of flood diversion in the water storage area is obvious, but the water storage area is limited by storage capacity. Once the water volume exceeds the storage capacity, the water storage area will lose the ability to changes in the upstream section and the downstream section are reversed, and the interval inflow is also the same. In terms of interval inflow and outflow, the conclusions drawn by the two are also opposite. This phenomenon is consistent with the actual situation, because when the interval inflow occurs, it can be known from the principle of water balance that the amount of water in the downstream section is inevitably reduced, and the water level and flow rate are naturally reduced. When the interval inflow occurs, the water level and flow rate of the upper and lower sections will naturally increase due to the increase of the water volume in the river channel.

\subsection{Analysis of the effect of different flood diversion methods}

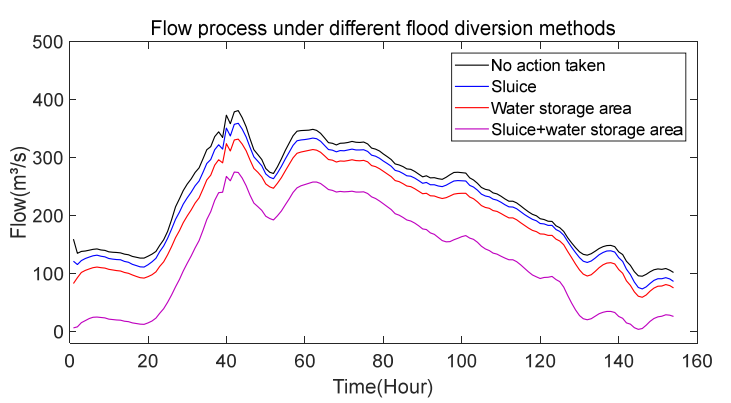

(b)

divert flood. Sluice control is a relatively flexible means of flooding, which is common in river networks in plain areas. We compared the changes of the water level of the rivers under different outflows of different gates. As shown in Fig.8, the dispatching of the sluice plays a role in flood diversion, but the effect of flood diversion is not obvious. Fig. 8 shows the results of the flood diversion in combination with the water storage area and the sluice, the combined method is more effective than the single flood diversion method.

\section{Conclusion}


This paper proposed a hydrodynamic (HD) model coupled multiple scenarios that may occur in plain river network, which was used to simulate the runoff process of the plain river network. The simulation results in 4.3 show that the proposed model is suitable for river runoff simulation in plain river network. In the selected 4 runoff events, the simulation accuracy of the water level is always higher than the simulation accuracy of the flow. Moreover, the runoff simulation accuracy of runoff events with large runoff is relatively high. At the same time, HD model coupled with multiple application scenarios can accurately simulate the outflow and inflow of rivers and the flood diversion of water storage areas and sluices. The effect of water storage and flood separation is more obvious than that sluices, and the flood diversion method combined with sluice and water storage area has better flood diversion effect. The above two flood diversion methods have their own characteristics. The sluices are flexible but the amount of flood discharge is limited, while the water storage has large flood discharge but difficult to control.

To obtain better simulation results, the hydrodynamic simulation of the river network in the plain area needs to consider more scenarios. The model proposed in this paper satisfies the practical application and reserves an interface for coupling hydrological model. The coupling of the hydrological model and the hydrodynamic model will provide flood-forecasting services for the plain river network, which will have important practical significance for flood control and disaster mitigation.

\section{References}

1. Adamovic, M., Branger, F., Braud, I., Kralisch, S., 2016. Development of a data-driven semi-distributed hydrological model for regional scale catchments prone to Mediterranean flash floods. Journal of Hydrology, 541: 173-189. DOI:https://doi.org/10.1016/j.jhydrol.2016.03.032

2. Ajami, H., Khan, U., Tuteja, N.K., Sharma, A., 2016. Development of a computationally efficient semi-distributed hydrologic modeling application for soil moisture, lateral flow and runoff simulation. Environmental Modelling \& Software, 85: 319-331. DOI:https://doi.org/10.1016/j.envsoft.2016.09.002

3. Andrew, R., Guan, H., Batelaan, O., 2017. Estimation of GRACE water storage components by temporal decomposition. Journal of Hydrology, 552: 341-350.

DOI:https://doi.org/10.1016/j.jhydrol.2017.06.016

4. Baugh, C.A., Bates, P.D., Schumann, G., Trigg, M.A., 2013. SRTM vegetation removal and hydrodynamic modeling accuracy. Water Resources Research, $\quad$ 49(9): 5276-5289. DOI:10.1002/wrcr.20412

5. de Paiva, R.C.D. et al., 2013. Large-scale hydrologic and hydrodynamic modeling of the Amazon River basin. Water Resources Research, 49(3): 1226-1243. DOI:10.1002/wrcr.20067
6. Hamilton, S.K., 2009a. Flood Plains. In: Likens, G.E. (Ed.), Encyclopedia of Inland Waters. Academic Press, Oxford, pp. 378-386. DOI:https://doi.org/10.1016/B978-012370626-3.000 $\underline{52-1}$

7. Hamilton, S.K., 2009b. Wetlands of Large Rivers: Flood plains. In: Likens, G.E. (Ed.), Encyclopedia of Inland Waters. Academic Press, Oxford, pp. 607-610. DOI:https://doi.org/10.1016/B978-012370626-3.000 $\underline{65-X}$

8. Hardy, J. et al., 2016. A method for probabilistic flash flood forecasting. Journal of Hydrology, 541: 480-494.

DOI:https://doi.org/10.1016/j.jhydrol.2016.04.007

9. Kałuża, T. et al., 2018. Plant basket hydraulic structures (PBHS) as a new river restoration measure. Science of The Total Environment, 627: 245-255. DOI:https://doi.org/10.1016/j.scitotenv.2018.01.029

10. Kim, N., Kawano, H., 1995. Simultaneous Solution for Flood Routing in Channel Networks, 121. DOI:10.1061/(ASCE)0733-9429(1995)121:10(744)

11. Liu, L., Gao, C., Xuan, W., Xu, Y.-P., 2017. Evaluation of medium-range ensemble flood forecasting based on calibration strategies and ensemble methods in Lanjiang Basin, Southeast China. Journal of Hydrology, 554: 233-250. DOI:https://doi.org/10.1016/j.jhydrol.2017.08.032

12. Lohani, A.K., Goel, N.K., Bhatia, K.K.S., 2014. Improving real time flood forecasting using fuzzy inference system. Journal of Hydrology, 509: 25-41. DOI:https://doi.org/10.1016/j.jhydrol.2013.11.021

13. Munar, A.M. et al., 2018. Coupling large-scale hydrological and hydrodynamic modeling: Toward a better comprehension of watershed-shallow lake processes. Journal of Hydrology, 564: 424-441. DOI:https://doi.org/10.1016/j.jhydrol.2018.07.045

14. Piper, G., 2014. Balancing flood risk and development in the flood plain: the Lower Thames Flood Risk Management Strategy. Ecohydrology \& Hydrobiology, $\quad$ 14(1): 33-38. DOI:https://doi.org/10.1016/j.ecohyd.2014.02.004

15. Radfar, M., Van Camp, M., Walraevens, K., 2013. Drought impacts on long-term hydrodynamic behavior of groundwater in the tertiary-quaternary aquifer system of Shahrekord Plain, Iran, 70. DOI:10.1007/s12665-012-2182-1

16. Salunkhe, S. et al., 2018. Flood Inundation Hazard Modelling Using CCHE2D Hydrodynamic Model and Geospatial Data for Embankment Breaching Scenario of Brahmaputra River in Assam, 46, 915-925 pp. DOI:10.1007/s12524-018-0749-3

17. W. Choi, G., Molinas, A., 1993. Simultaneous Solution Algorithm for Channel Network Modeling, 29, 321-328 pp. DOI:10.1029/92WR01949

18. $\mathrm{Wu}, \mathrm{Y}$. et al., 2018. Quantifying the unauthorized lake water withdrawals and their impacts on the water budget of eutrophic lake Dianchi, China. 
Journal of Hydrology, 565: 39-48.

DOI:https://doi.org/10.1016/j.jhydrol.2018.08.017

19. Zernin, M.V., Mishin, A.V., Rybkin, N.N., 2017.

Estimation of Hydrodynamic Parameters of

Connecting Rod Plain Bearings of Pumping Plant of

Powered Mine Support. IOP Conference Series:

Earth and Environmental Science, 87(8): 082058. 